\title{
The effect of intravenous flumazenil on interictal electroencephalographic epileptic activity: results of a placebo-controlled study
}

\author{
Y M Hart, Hermelijn Meinardi, JWAS Sander, D J Nutt, S D Şhorvon
}

\begin{abstract}
The effect on interictal electroencephalographic epileptic activity of intravenous flumazenil (Ro 15-1788), a benzodiazepine antagonist and potent:al antiepileptic drug, was studied in 10 patients. Comparison was made with intravenous diazepam (10 $\mathrm{mg})$ and placebo using a single-blind, single-dose, cross-over design. A dose of $3 \mathrm{mg}$ flumazenil was well tolerated and produced a significantly greater reduction in the number of epileptic transients during the first $\mathbf{4 0}$ minutes after injection than did placebo $(p<0.05)$. This effect was similar to that of diazepam in magnitude and duration. When flumazenil (3 mg) was administered immediately after intravenous diazepam (10 $\mathrm{mg})$, the reduction in interictal epileptic activity was not significantly different from that produced by diazepam alone. The results suggest that either flumazenil has intrinsic antiepileptic activity and in this respect acts as a partial agonist at the benzodiazepine receptor, or that it is antagonising an endogenous proconvulsant ligand in these patients.
\end{abstract}

INSEG (Institute of Neurology, The National Hospital and National Society for Epilepsy Research Group), Institute of Neurology, Queen Square, London, and National HospitalChalfont Centre for Epilepsy, Chalfont St Peter,

Buckinghamshire, UK Y M Hart

H Meinardi

J W A S Sander

$S$ D Shorvon

Reckitt and Colman Psychopharmacology Unit, School of Medical Sciences, Bristol Bristol

Correspondence to: Dr Hart,

National Hospital-Chalfont Centre for Epilepsy, Chalfont St Peter, Buckinghamshire SL9 ORJ, UK.

Received 22 March 1990 and in revised form 20 August 1990 . Accepted 2 October 1990
Flumazenil (Ro 15-1788) (ethyl 8-fluoro-5,6dihydro-5-methyl-6-oxo-4H-imidazo-[1,5-a] [1,4]-benzodiazepine-3-carboxylate) is a potent benzodiazepine (BDZ) receptor antagonist which has been extensively studied in the management of $\mathrm{BDZ}$ overdose and in terminating BDZ-induced anaesthesia. ${ }^{1}$ Recent studies in animals, ${ }^{2}$ as well as preliminary work in humans, ${ }^{3}$ have suggested that flumazenil may also have anticonvulsant properties, although it did not induce sedation or show anxiolytic properties. Furthermore, flumazenil has been suggested as decreasing tolerance development to $\mathrm{BDZs}$ and since this is a common clinical limitation of $\mathrm{BDZ}$ therapy for epilepsy, flumazenil might have therapeutic value in this field.

This study was set up to investigate three questions. The first was to see if flumazenil had antiepileptic action by comparing the effect of three doses with $10 \mathrm{mg}$ diazepam and placebo on interictal electroencephalographic epileptic activity (IEA). The second was to determine the onset of action and duration of activity of intravenous flumazenil in this pharmacodynamic model, and to assess the tolerability of single doses of flumazenil in adult patients under treatment with various concomitantly administered antiepileptic drugs (AEDs). Finally, because flumazenil is a $B D Z$ receptor antagonist, its administration to people in conjunction with diazepam (for example, in its potential capacity of preventing tolerance to $\mathrm{BDZs}^{4}$ or in the treatment of intractable status epilepticus) could theoretically abolish any anticonvulsant effect of the diazepam and worsen seizures. Therefore the effect of flumazenil given immediately after diazepam on IEA was also investigated.

\section{Methods}

The study was a single-blind, randomised, placebo-controlled, cross-over, single-dose study of the effects of intravenous flumazenil $(0.5,1.0$ and $3.0 \mathrm{mg})$ compared with intravenous placebo and intravenous diazepam (10 $\mathrm{mg}$ ) on the IEA of adult inpatients with epileptic seizures of various types (table 1 ). The doses of flumazenil were chosen on the basis of the work of others using PET scanning which suggests that 1 or $2 \mathrm{mg}$ flumazenil should produce about $50 \%$ receptor occupation in the brain. $^{5}$

Ten patients were studied (table 1). All were resident at an epilepsy centre, and each patient had consistent IEA in the EEG. Patients were excluded if they had received BDZs in the month before entry (except as a single dose at least one week before study), if they had a history of sensitivity or allergy to BDZs, if they suffered from any relevant organic systemic or psychiatric diseases other than epilepsy, or if they were taking more than three AEDs or had had changes made to their AEDs in the month before entry. Patients were also excluded if they had clinically relevant abnormal laboratory tests on entry to the study, and female patients were required to have a negative pregnancy test. Written consent was obtained from each patient, and the study was approved by the Medical Ethics Committee of the National Hospital for Nervous Diseases.

The study days for each patient were separated by intervals of not less than one week. During the week before the first study day, a medical history was taken, patients had a full physical and neurological examination, and baseline laboratory tests (haematology, serum chemistry, including plasma levels of concomitant AEDs, and urinalysis) were per- 
Table 1 Details of patients

\begin{tabular}{|c|c|c|c|c|c|c|}
\hline Patient & Age & Sex & $\begin{array}{l}\text { Age at onset } \\
\text { of epilepsy }\end{array}$ & $\begin{array}{l}\text { Aetiology of } \\
\text { epilepsy }\end{array}$ & $\begin{array}{l}\text { Seizure } \\
\text { types }\end{array}$ & $\begin{array}{l}\text { Concurrent } \\
\text { AEDs }\end{array}$ \\
\hline 1 & 43 & $\mathbf{F}$ & 4 & Cryptogenic & $\mathrm{B} / \mathrm{C}$ & $\begin{array}{l}\text { CBZ } \\
\text { SVP }\end{array}$ \\
\hline 2 & 37 & $\mathbf{M}$ & 3 & Cryptogenic & $\mathrm{B} / \mathrm{C}$ & $\begin{array}{l}\text { CBZ } \\
\text { PHT }\end{array}$ \\
\hline 3 & 45 & $\mathbf{M}$ & 2 & Post-traumatic & $\mathrm{A} / \mathrm{B} / \mathrm{C}$ & $\begin{array}{l}\text { CBZ } \\
\text { PHT } \\
\text { LTG }\end{array}$ \\
\hline $\begin{array}{l}4 \\
5 \\
6\end{array}$ & $\begin{array}{l}34 \\
38 \\
35\end{array}$ & $\begin{array}{l}\mathbf{M} \\
\mathbf{M} \\
\mathbf{M}\end{array}$ & $\begin{array}{l}1 \\
1 \\
4\end{array}$ & $\begin{array}{l}\text { Post-traumatic } \\
\text { Cryptogenic } \\
\text { Perinatal injury }\end{array}$ & $\begin{array}{l}\mathrm{B} / \mathrm{C} \\
\mathrm{B} / \mathrm{C} \\
\mathrm{B} / \mathrm{C}\end{array}$ & $\begin{array}{l}\text { CBZ } \\
\text { CBZ } \\
\text { CBZ }\end{array}$ \\
\hline 7 & 34 & $\mathbf{M}$ & 9 & Cryptogenic & $\mathrm{B} / \mathrm{C}$ & $\begin{array}{l}\text { PHT } \\
\text { CBZ } \\
\text { PRM }\end{array}$ \\
\hline 8 & 62 & $\mathbf{M}$ & 3 & Cryptogenic & $\mathrm{B} / \mathrm{C}$ & $\begin{array}{l}\text { CBZ } \\
\text { SVP }\end{array}$ \\
\hline 9 & 41 & $\mathbf{M}$ & 12 & Post-traumatic & $\mathrm{B} / \mathrm{C}$ & $\begin{array}{l}\text { PHT } \\
\text { PRM }\end{array}$ \\
\hline 10 & 32 & $\mathbf{M}$ & 10 & Cryptogenic & $\mathrm{A} / \mathrm{B} / \mathrm{C}$ & $\begin{array}{l}\text { PHB } \\
\text { CBZ } \\
\text { MSM }\end{array}$ \\
\hline
\end{tabular}

$\mathrm{A}=$ simple partial seizures; $\mathrm{B}=$ complex partial seizures; $\mathrm{C}=$ secondarily generalised seizures. $\mathrm{CBZ}=$ carbamazepine; LTG = lamotrigine; MSM = methsuximide; $\mathrm{PHB}=$ phenobarbitone; $\mathrm{PHT}=$ phenytoin; $\mathrm{PRM}=$ primidone; $\mathrm{SVP}=$ sodium valproate.

formed. A recent routine EEG examination was also available for all patients.

On each of the first five study days patients received in a single-blind manner an intravenous injection of either placebo, flumazenil $0.5 \mathrm{mg}$, flumazenil $1 \mathrm{mg}$, flumazenil $3 \mathrm{mg}$, or diazepam $10 \mathrm{mg}$, the sequence of drugs being random. EEG monitoring was carried out for 60 minutes before and after administration of the drug. The electrodes were placed according to the International 10-20 system and recording was made from the lateral ring of electrodes. Vital signs (pulse, blood pressure and temperature) were monitored prior to the drug being given and at 15 and 30 minutes afterwards, and blood samples for estimation of AEDs were taken 10 minutes prior to the test drug being given and at five, 30 and 60 minutes afterwards. Efforts were made to ensure that as far as possible a uniform level of alertness was maintained during the study. After each study day patients were questioned about possible side effects.

On the sixth study day, in order to assess the effect of flumazenil given in conjunction with diazepam on IEA, $10 \mathrm{mg}$ diazepam followed immediately by $3 \mathrm{mg}$ flumazenil (chosen because this was the dose which had previously been most effective) was given by slow intravenous injection. This part of the study was not carried out "blind". EEG monitoring and monitoring of vital signs were carried out as for the other study days, but blood samples were not taken. Seven patients were studied for this sixth day.

Following the last study day a further physical and neurological examination was undertaken and the laboratory tests carried out at the beginning of the study were repeated.

IEA was quantified in the lead in which the epileptic discharges were most clearly defined. Counting of the epileptic transients was carried out blind to the drug given, the counts being divided into two-minute epochs. The epileptic abnormalities taken into account were spikes, polyspikes, spike and waves, and sharp waves. A spike was defined as a wave distinguished from background activity owing to its abrupt occurrence, its higher amplitude than background activity, and having a duration of less than $70 \mathrm{~ms}$. Polyspikes were constituted by the succession of several isolated spikes, and were counted as single epileptic transients. Spike and waves consisted of spikes followed by a slow delta wave, with a frequency of $2 \cdot 5-5 \mathrm{~Hz}$. Sharp waves were defined as isolated slow waves mainly of delta type, notched by a spike in their ascending or descending part, and of not more than $200 \mathrm{~ms}$ duration. They were included in the quantification where they were clearly of epileptic origin, that is, accompanied by spikes, present in adjacent channels, or where they were phase-reversing.

In view of the short half-life of flumazenil, and in order not to miss a short-lived effect, the time after drug administration was divided into three 20 minute time intervals $(0-20$ mins, 20 40 mins, $40-60 \mathrm{mins}$ ). To assess the efficacy of each drug in reducing IEA multivariate analysis of variance was performed on the square roots of the means of the spike counts, which were normally distributed, using contrasts to compare the effect of each drug with placebo, the effect of time following drug administration with the period before drug administration, and the interaction between the two. When comparing the results of the sixth study day, only those seven patients taking part were included in the analysis.

\section{Results}

Table 1 shows the clinical characteristics of the patients taking part in the study. Figure 1 shows a graph of the mean counts of epileptic transients against time.

During the first two 20 minute periods following drug administration, flumazenil $3 \mathrm{mg}$ was associated with a significantly greater reduction in IEA than placebo $(p<0.01$ and $\mathrm{p}<0.05$ respectively) (table 2 ). Diazepam 10 mg was also associated with a significantly greater reduction in IEA than placebo in the time period $20-40$ minutes $(p<0.05)$. 


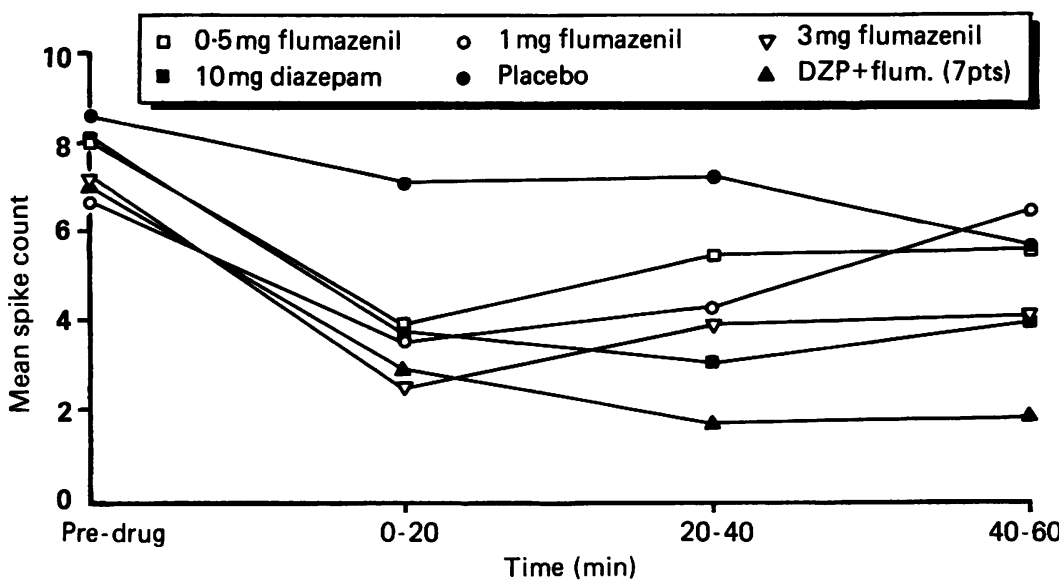

Figure Interictal epileptic activity (all patients).

Table 3 shows the comparison between the effect on IEA of flumazenil $3 \mathrm{mg}$ given in conjunction with diazepam against that of placebo, flumazenil $3 \mathrm{mg}$ and diazepam $10 \mathrm{mg}$. Although it was not quantified objectively, the drowsiness which tended to occur following administration of diazepam alone appeared considerably reduced when the drug was given in conjunction with flumazenil. The effect of the two drugs given in combination was significantly greater than that of placebo for the first 40 minutes following injection $(p<0.01$ and $\mathrm{p}<0.05$ for the periods $0-20$ and 20-40 minutes, respectively). No significant difference could be demonstrated between the effect of the two drugs together and that of diazepam given alone for the whole hour following drug administration. When the effect of flumazenil $3 \mathrm{mg}$ given alone was compared with that of the two drugs together, however, the effects were only comparable for the first 20 minutes following injection.

Minor changes only were noted in the biochemical and haematological parameters

Table 2 Results of multivariate analysis of variance (drug by time interaction)

a Comparison of effect of flumazenil $0.5 \mathrm{mg}$ on IEA with that of placebo

Time after

$\begin{array}{clll}\text { injection (mins) } & F & D F & P \\ 0-20 & 3.79 & 1,9 & 0.08 \\ 20-40 & 0.67 & 1,9 & 0.44 \\ 40-60 & 0.07 & 1,9 & 0.80\end{array}$

b Comparison of effect of flumazenil $1 \mathrm{mg}$ on IEA with that of placebo

Time after

$\begin{array}{clll}\text { injection (mins) } & F & D F & P \\ 0-20 & 2 \cdot 83 & 1,9 & 0.13 \\ 20-40 & 1.00 & 1,9 & 0.34 \\ 40-60 & 0.99 & 1,9 & 0.35\end{array}$

c Comparison of effect of flumazenil $3 \mathrm{mg}$ on IEA with that of placebo

Time after

$\begin{array}{cccl}\text { injection (mins) } & F & D F & P \\ 0-20 & 19.43 & 1,9 & 0.002 \\ 20-40 & 5.23 & 1,9 & 0.05 \\ 40-60 & 1.42 & 1,9 & 0.26\end{array}$

d Comparison of effect of diazepam $10 \mathrm{mg}$ on IEA with that of placebo

\begin{tabular}{clll}
$\begin{array}{c}\text { Time after } \\
\text { injection (mins) }\end{array}$ & $F$ & $D F$ & $P$ \\
$0-20$ & 3.91 & 1,9 & 0.08 \\
$20-40$ & 5.05 & 1,9 & 0.05 \\
$40-60$ & 0.97 & 1,9 & 0.35 \\
\hline
\end{tabular}

Table 3 Results of multivariate analysis of variance (drug by time interaction)

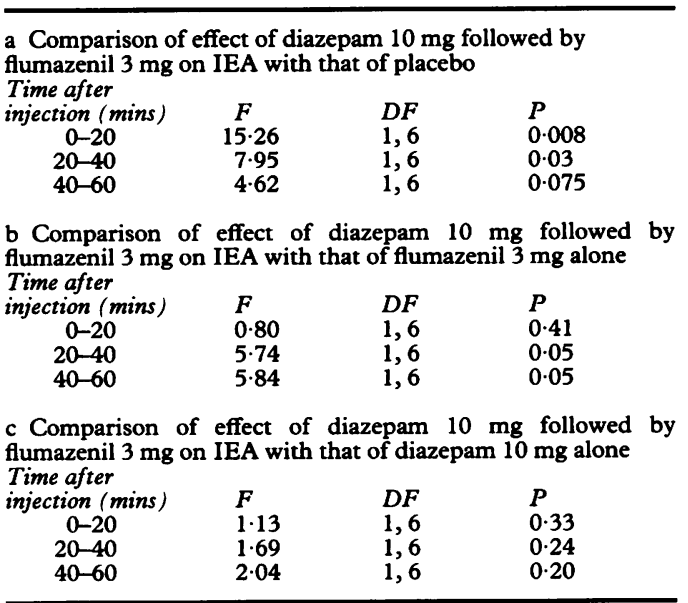

measured on the screening days at the beginning and end of the study, and none of these was considered to be of clinical importance. No significant changes were caused by flumazenil in any of the blood levels of the concomitant AEDs. No direct relationship was found between plasma concentration of flumazenil and effect on IEA.

No major adverse effects to flumazenil were noted on study days. One patient became unexpectedly tearful and upset after being given flumazenil in conjunction with diazepam, but she had not shown any untoward reaction when given flumazenil alone. Another patient was sedated excessively and developed respiratory depression when given diazepam alone, and had to be excluded from the second phase of the study.

\section{Discussion}

The major finding of the present study is that flumazenil, a BDZ antagonist, has an antiepileptic action equivalent to that of diazepam in a model for screening potential AEDs. The suppression of interictal activity is a simple and rapid method for the preliminary assessment of potential AEDs, which has been shown to demonstrate anticonvulsant activity of a number of established AEDs including sodium valproate, ${ }^{6}$ phenytoin ${ }^{7}$ and diazepam. ${ }^{8}$ It does have limitations ${ }^{910}$; for instance, the amount of IEA does not necessarily reflect seizure frequency $^{\text {11 }}$ (and with some drugs, such as carbamazepine, IEA may even increase despite decreased seizure frequency ${ }^{12}$ ), and there is also commonly considerable variation in counts of epileptic transients between individuals and in the same individual at different times, in part associated with variables such as time of day and the degree of alertness of the patient. ${ }^{13}$ Nevertheless, this study demonstrated a significant antiepileptic action of diazepam. Surprisingly in this group of patients intravenous flumazenil at a dose of $3 \mathrm{mg}$ was also effective in suppressing IEA, the magnitude of its effect being comparable with that of $10 \mathrm{mg}$ diazepam for the first $\mathbf{4 0}$ minutes after administration. The onset of action of intravenous flumazenil was faster than that of diazepam, occurring 
within minutes of injection. Smaller doses of flumazenil were not demonstrated to have a significant effect on IEA, although a trend in this direction at 0-20 minutes was seen for each dose.

The mechanism by which flumazenil, a BDZ antagonist, may display antiepileptic action may be surmised from our current knowledge of the $\mathrm{BDZ}$ receptor. This suggests that the $B D Z$ receptor is an integral part of the $\mathrm{GABA}_{\mathrm{A}}$ receptor complex ${ }^{14}$, and acts as a modulatory unit, with its ligands altering the GABAmediated gating of the chloride channel in the receptor complex. The $\mathrm{BDZ}$ receptor has been postulated to be unusual in having three types of ligand. ${ }^{2}$ In this model, the classic benzodiazepines are thought to be agonists, which stabilise an "active" conformation of the receptor, associated with an increase in the effects of the inhibitory transmitter GABA, and are thus anticonvulsant and anxiolytic, while inverse agonists such as ethyl $\beta$ carboline-3-carboxylate $(\beta$-CCE) bind to a different conformation, decreasing the action of GABA, and have proconvulsant and anxiogenic effects. Antagonists such as flumazenil are thought to have affinity for both forms or for a "neutral" conformation, leaving the equilibrium unaltered. ${ }^{15}$ It has become clear, however, that full agonists and inverse agonists represent the two ends of a spectrum, in that partial agonists and partial inverse agonists with some intrinsic activity in either direction ${ }^{16}$ also exist.

Based on this model, there are three possible explanations for the action of flumazenil in reducing IEA. First, it may act as a partial agonist, producing an anticonvulsant effect at high doses which approximate to receptor saturation. Second, it may antagonise the action of an endogenous proconvulsant ligand, that would be contributing to the IEA (and possibly the epileptic activity) in these patients. The third possibility is that the "set point" of the BDZ receptor spectrum is different in people with epilepsy compared with controls, so that flumazenil is, even at low doses, a weak partial agonist.

Dissociating these possibilities is not easy. The coming availability of partial agonists such as Ro $16-6028^{17}$ will allow the testing of such compounds on IEA. If they are less effective than flumazenil this will argue against the partial agonist theory. A variety of endogenous ligands has been suggested ${ }^{18}$ but, with the exception of desmethyldiazepam ${ }^{19}$ none has been properly confirmed. One possible candidate is diazepam binding inhibitor (DBI) which has been reported to have inverse agonist properties. $^{20}$ To date, levels of DBI in cerebrospinal fluid appear not to have been measured in epilepsy, although they are increased in depression. ${ }^{21}$ Another purported endogenous inverse agonist is tribulin, ${ }^{22}$ whose excretion is elevated in benzodiazepine withdrawal. ${ }^{23}$ Further studies on the cerebrospinal fluid and post-mortem brains of people with epilepsy are warranted.

The third possibility is that the receptor set point is shifted in the agonist direction in people with epilepsy. This would make flumazenil a partial agonist, rather than an antagonist. A receptor shift in the other direction has been reported in benzodiazepine withdrawal, ${ }^{12}{ }^{13}$ so the reverse is possible. This study would be the first evidence for what might be an adaptive response to seizure activity. It should, however, be noted that many of the AEDs that the patients were taking may also interact with BDZ receptors, for example, phenytoin has been shown to increase $\mathrm{BDZ}$ binding and function, ${ }^{24}$ and barbiturates indirectly interact with benzodiazepine binding. ${ }^{25} \mathrm{Car}$ bamazepine can act at the $\mathrm{BDZ}$ receptor in high doses $^{26}$ and valproate may act at the GABA/ $\mathrm{BDZ}$ receptor complex. ${ }^{27}$ In view of these complicating interactions it will be of great interest to try flumazenil in people with untreated epilepsy.

It may be that flumazenil will prove to have anticonvulsant action in full seizures as well as on IEA. If this is the case, then a major advantage would be that it does not have the sedative properties of diazepam and many of the other commonly used BDZs. Further studies into the potential of flumazenil as an AED, especially in emergency settings where its safety would be of great merit, are warranted. Additionally, it would be important to assess its efficacy on oral administration.

Another possible use of flumazenil may be in preventing the development of tolerance in patients with epilepsy responding to BDZs. Gonsalves and Gallager have shown in experiments with rodents and baboons ${ }^{428}$ that a single exposure to flumazenil during $\mathrm{BDZ}$ treatment can prevent tolerance, and that periodic administration can prevent the subsequent development of withdrawal responses. However, in animal studies of chemicallyinduced seizures, flumazenil abolishes the anticonvulsant effect of diazepam because of its antagonistic action at the $\mathrm{BDZ}$ receptor. If this were seen clinically, there would also be a risk of further seizures if flumazenil were given to reverse $\mathrm{BDZ}$ tolerance in patients with epilepsy. In our study, however, flumazenil did not diminish the reduction in IEA caused by diazepam, although it did appear to reverse the drowsiness; further studies are warranted to confirm this observation. These findings are consistent with a partial agonist effect of flumazenil blocking the sedative effects of the full agonist diazepam ${ }^{29}$ without decreasing the anticonvulsant ones. They offer hope that the administration of flumazenil to patients already on BDZs may not precipitate withdrawal or promote seizures. Thus studies into the possibility of using flumazenil to prevent the development of tolerance during $\mathrm{BDZ}$ use may well be practicable.

In summary, we have shown that intravenous flumazenil reduces IEA and was well tolerated without significant side effects. Additionally, it did not diminish the antiepileptic effect of diazepam. These findings may be evidence for proconvulsant endogenous ligands or altered receptor function in epilepsy, and could lead to new treatments for seizures and for $\mathrm{BDZ}$ tolerance. 
We would like to acknowledge the support of the Brain Research Trust, the National Fund for Research into Crippling Diseases and the Sir Jules Thorn Charitable Trust. We are grateful to Roche for supplies of the drugs used. We thank Mrs Margaret Roberts and Mrs Denise Grundy for their technical assistance, Joan Morris and Peter Sacares for their statistical help, and al the patients who took part.

1 Flumazenil. Lancet (editorial) 1988;ii:828-9.

2 Nutt DJ, Cowen PJ, Little HJ. Unusual interactions of benzodiazepine receptor antagonists. Nature 1982; 295:436-8.

3 Scollo-Lavizzari G. The anticonvulsant activity of the benzodiazepine antagonist Ro 15-1788. An EEG study in 4 cases. Eur Neurol 1984;23:1-6.

4 Gonsalves SF, Gallager DW. Persistent reversal of tolerance to anticonvulsant effects and GABAergic subsensitivity by a single exposure to benzodiazepine antagonist during chronic benzodiazepine administration. J Pharmacol Exp Ther 1988;244:79-83.

5 Persson A, Pauli S, Halldin C, et al. Saturation analysis of specific [11]C-Ro 15-1788 binding to the human neocortex using positron emission tomography. Human Psychopharm 1989;4:21-31.

6 Villarreal HJ, Wilder BJ, Willmore LJ, Bauman AW, Hammond EJ, Bruni J. Effect of valproic acid on spike and wave discharges in patients with absence seizures. Neurology 1978;28:886-91.

7 Milligan N, Oxley J, Richens A. Acute effects of intravenous phenytoin on the frequency of inter-ictal spikes in man. $B r$ phenytoin on the frequency of in

8 Milligan N, Dhillon S, Oxley J, Richens A. Absorption of diazepam from the rectum and its effect on interictal spikes in the EEG. Epilepsia 1982;23:323-31.

9 Milligan N, Richens A. Methods of assessment of antiepileptic drugs. Br J Clin Pharmac 1981;11:443-56.

10 Binnie CD. The use of the inter-ictal EEG in the study of antiepileptic drugs. In: PA Buser, WA Cobb, T Okuma eds. Kyoto Symposia. Electroenceph Clin Neurophysiol, (Suppl 36). Amsterdam: Elsevier Biomedical Press, 1982 504-12

11 Gotman J, Marciani MG. Electroencephalographic spiking activity, drug levels, and seizure occurrence in epileptic patients. Ann Neurol 1985;17:597-603.

12 Sachdeo $\mathrm{R}$, Chokroverty $\mathrm{S}$. Increasing epileptiform activities in EEG in presence of decreasing clinical activities in EEG in presence of decreasing clinical
seizures after carbamazepine. Epilepsia 1979;20:522.

13 Martins da Silva A, Aarts JHP, Binnie CD, et al. The circadian distribution of interictal epileptiform activity. Electroenceph clin Neurophysiol 1984;58:1-13.
14 Mohler H, Richards JG. The benzodiazepine receptor. A pharmacological control element of brain function. Eur $J$ pharmacological control element

15 Little HJ, Nutt DJ, Taylor SC. Bidirectional effects of chronic treatment with agonists and inverse agonists at the benzodiazepine receptor. Brain Res Bull 1987;19:371-78.

16 Little HJ, Nutt DJ, Taylor SC. Kindling and withdrawal changes at the benzodiazepine receptor. J Psychopharmacol 1987;1:35-6.

17 Martin JR, Pieri L, Bonetti EP, et al. Ro-16-6028: A novel anxiolytic acting as a partial agonist at the benzodiazepine receptor. Pharmacopsychiatry 1988;21:360-2.

18 Haefely $W$. Endogenous ligands of the benzodiazepine receptor. Pharmacopsychiatry 1988;21:43-46.

19 Sangameswaran L, Fales HM, Friedrich P, De Blas AL. Purification of a benzodiazepine from bovine brain and detection of benzodiazepine-like immunoreactivity in detection of benzodiazepine-like immunoreactivity in
human brain. Proc Natl Acad Sci US A 1986;83:9236-40.

20 Guidotti A, Forchetti CM, Corda MG, Konkel D, Bennett $\mathrm{CD}$, Costa $\mathrm{E}$. Isolation, characterization, and purification to homogeneity of an endogenous polypeptide with agonistic action on benzodiazepine receptors. Proc Natl Acad Sci USA 1983;80:3531-5.

21 Barbaccia ML, Costa E, Ferrero P, Guidotti A, et al. Diazepam-binding inhibitor. Arch Gen Psychiatry 1986, 43:1143-7.

22 Sandler M. The emergence of tribulin. TIPS 1983;3:471-2.

23 Petursson $H$, Bhattacharya SK, Glover $V$, Sandler M, Lader $\mathrm{MH}$. Urinary monoamine oxidase inhibitor and benzodiazepine withdrawal. Br J Psychiatr 1982;140:7-10.

24 Gallager DW, Mallorga P, Tallman JF. Interaction of diphenylhydantoin and benzodiazepines in the CNS. Brain Res 1980;189:209-20.

25 Olsen RW. GABA-benzodiazepine-barbiturate receptor interactions. J Neurochem 1981;37:1-13.

26 Nutt DJ, Little HJ, Taylor SC, Minchin MC. Investigating benzodiazepine receptor function in vivo using a intravenous infusion of DMCM. Eur $J$ Pharmacol 1984; 103:359-62

27 Ticku ML, Davis WC. Effect of valproic acid on $\left[{ }^{3} \mathrm{H}\right]$ diazepam and $\left[{ }^{3} \mathrm{H}\right]$ dihydropicrotoxinin binding sites at the benzodiazepine-GABA receptor-ionophore complex. Brain Res 1981;223:218-22.

28 Gallager DW, Heninger K, Heninger G. Periodic benzodiazepine antagonist administration prevents benzodiazepine withdrawal symptoms in primates. Eur $J$ Pharmacol 1986;132:31-38.

29 Haefely W. Partial agonists of the benzodiazepine receptor: from animal data to results in patients. In: Biggio G, Costa $\mathrm{E}$, eds. Chloride channels and their modulation by neurotransmitters and drugs. New York: Raven Press, 1988: transmitier. 